\title{
Legal concerns trigger prostate-specific antigen testing
}

\author{
Johan Steurer MD, ${ }^{1}$ Ulrike Held PhD, ${ }^{2}$ Mathias Schmidt MD, ${ }^{3}$ Gerd Gigerenzer $\mathrm{PhD}^{4}{ }^{4}$ Brigitte Tag $\mathrm{Dr}^{5}$ \\ and Lucas M. Bachmann MD PhD ${ }^{6}$
}

\author{
${ }^{1}$ Professor, ${ }^{2}$ Senior Researcher, ${ }^{3}$ Research Fellow, ${ }^{6}$ Deputy Director, Horten Centre for patient oriented research and knowledge transfer, \\ University of Zurich, Postfach Nord, $\mathrm{CH}-8091$ Zurich, Switzerland \\ ${ }^{4}$ Professor, Max Planck Institute for Human Development, Center for Adaptive Behavior \& Cognition, Berlin, Germany \\ ${ }^{5}$ Professor, Rechtswissenschaftliches Institut, Lehrstuhl für Strafrecht und Strafprozessrecht Universität Zürich, Switzerland
}

\author{
Keywords \\ defensive medicine, legal aspects, prostate \\ cancer, screening \\ Correspondence \\ Johan Steurer \\ Horten Centre for Patient Oriented \\ Research and Knowledge Transfer \\ University of Zurich \\ Postfach Nord \\ Zurich \\ CH-8091 Zurich \\ Switzerland \\ E-mail: johann.steurer@usz.ch \\ Accepted for publication: 27 February 2008
}

doi:10.1111/j.1365-2753.2008.01024.x

\begin{abstract}
Background In the United States, lawsuits against physicians have had an impact on their behaviour, resulting in overdiagnosis and other forms of 'defensive medicine'. Does a similar situation exist in Switzerland? Using prostate-specific antigen (PSA) screening as an example, we surveyed Swiss physicians and assessed the extent to which liability fears influenced their recommendation for testing.

Methods At a continuing medical education conference we distributed a pilot-tested questionnaire to 552 participants. Two hundred and fifty of them $(45 \%)$ completed the questionnaire.

Results Of the participants, 158 (68\%) were general practitioners and $73(32 \%)$ specialists in internal medicine. Seventy-five per cent of both groups recommend regular PSA screening to men older than age 50 . Yet only $56 \%$ of the general physicians and $53 \%$ of the internists believe that PSA measurement is an effective screening method. A substantial proportion of the physicians $-41 \%$ of general practitioners and $43 \%$ of internists - reported that they sometimes or often recommend this test for legal reasons.

Conclusions Defensive medicine is not a phenomenon particular to the USA, but is also observable in Switzerland. This result is surprising, given that in Switzerland and other European countries, a physician who does not recommend a test or treatment whose effectiveness is controversial need not fear litigation.
\end{abstract}

\section{Introduction}

In 2004, the case of Dr Daniel Merenstein triggered an intensive debate in scientific journals and media on defensive medicine [1-5]. Following the guidelines of several well-respected national organizations, Merenstein had explained the pros and cons of prostate-specific antigen (PSA) testing to a patient, rather than simply ordering the test. He then documented the shared decision not to order the test. Later, the patient was diagnosed with incurable advanced prostate cancer, and Merenstein and his residency were sued for not ordering the test. Although Merenstein was acquitted, his residency was found liable for $\$ 1$ million [6]. Ever since this ordeal, he regards his patients as potential plaintiffs: 'I order more tests now, am more nervous around patients: I am no longer the doctor I should be' [7].

The number of lawsuits against physicians in the USA has increased within the last decades and has had a substantial impact on the behaviour of physicians and medical practice. Physicians order tests and avoid treating high-risk patients in order to reduce their exposure to lawsuits, or are forced to discontinue practising because of overly high insurance premiums [8]. This behaviour has become known as defensive medicine, 'a deviation from sound medical practice that is indicated primarily by a threat of liability' [8]. It has spread to many areas of clinical medicine and is seen as a major factor in the increase in health care costs, estimated at tens of billions of dollars annually in the USA [9].

Several authors have argued that these developments observed in the USA are less distinctive in European countries [10,11]. Indeed, the law or tort system is different in the USA than in most European countries; for instance, the number of lawsuits against physicians in the UK is much lower than in the USA [12]. In Switzerland, the number of claims processed through the conventional legal system is not available, but experts assume that they are substantially lower than in the USA and UK. Our question was whether these differences in legal systems would be reflected in a difference in perceived threat of liability. Using PSA screening as an example, we surveyed Swiss general physicians about their beliefs related to the benefits of screening and assessed to what extent liability fears influenced their recommendations for testing. 


\section{Methods}

\section{Participants}

We recruited family physicians and general internists attending a continuing medical education conference in January 2007 in the German-speaking part of Switzerland. Questionnaires were distributed in envelopes before the meeting. Participants of the conference were asked to fill out the questionnaire during a 10-minute break and to hand it in at the end of the session. Those who wanted to complete the questionnaire after the meeting were given a week's time to send the form to the study centre by surface mail.

\section{Questionnaire}

The questionnaire, which was developed and pilot tested on a different group of 40 doctors, consisted of two parts. In the first part, we requested details on the participants' age, gender and medical specialty. In the second part, we collected information on the participants' knowledge of the benefits of regular screening for prostate cancer. Furthermore, we asked whether the physicians generally recommend this test to their clients and undergo PSA testing themselves. Another question was whether relatives or friends were diagnosed with prostate cancer within the last 5 years. It was also asked whether legal issues were (sometimes or often) the reason for recommending screening tests.

\section{Data analysis}

The data were stored in EPIDATA (http://www.epidata.dk/) and analyses were performed with the statistical software package Stata 9.2 (4905 Lakeway Drive, College Station, TX, USA). The percentage of missing data for survey questions ranged from $0 \%$ to $1.7 \%$. Missing values have been excluded from the analyses in all percentages reported.

\section{Results}

Of the 552 participants attending the educational session, 250 (45\%) returned the questionnaire, 245 immediately after the lecture and five by surface mail within 1 week. Nineteen participants were excluded from further analysis, because they were neither general physicians nor internists $(n=13)$ or because of missing information about age and/or gender $(n=6)$. The median age of all participants was 52 years (range 28-67); 177 (77\%) were male (median age 54, range 30-67) and $54(23 \%)$ female (median age 45 , range 28-64). One hundred and fifty-eight (68\%) of the participants were general practitioners and $73(32 \%)$ specialists in internal medicine.

Only about half of the physicians (56\% of the general physicians and $53 \%$ of internists) believe that regular PSA screening is an effective test and that its advantages outweigh potential harm. In both groups of physicians, $75 \%$ recommend regular PSA screening to men older than 50 years of age. Forty-one per cent of general practitioners and $43 \%$ of internists stated that they sometimes or often recommend this test for legal reasons.

\section{Discussion}

Around half of the participating physicians believe that the advantages of PSA screening in men older than age 50 outweigh potential harm, yet three quarters of them recommend that their patients undergo the test. This discrepancy that more physicians recommend the test than believe that the test is effective can be explained by physicians' legal concerns. Apart from legal concerns, monetary motives could also affect the physicians' behaviour. However, as a physician ordering a PSA test earns less than 10 Swiss francs, we assume that monetary motives play only a minor role.

To our knowledge this is the first study testing how many physicians believe that PSA testing is beneficial, i.e. the advantages outweigh potential harm, and how many recommend this test to their patients. In an earlier study, Australian physicians were only surveyed about PSA testing. Although the Australian guidelines do not recommend regular testing, nearly all of the surveyed physicians recommend this test to men over 50 years of age and only about one-quarter of them knew that Australian general physicians are legally protected when they do not conduct PSA testing on men above age 50 who are later diagnosed with prostate cancer [13].

The result of our survey is an indication that defensive medicine exists in Switzerland. A substantial proportion of physicians recommend PSA tests not primarily to benefit their patients but to reduce their own risk of exposure to malpractice liability. Defensive medicine is not necessarily without any benefits to the patient, but it does have a major impact on health care costs, through both the direct costs of the test and the potential additional expenses of follow-up tests. Precise cost data are not known; it is estimated that in the USA, the costs of defensive medicine amount to tens of millions of dollars annually [9].

The tort system has a twofold impact on medical care. When doctors have acted negligently and caused injury to patients, common law obliges them to compensate for damages. On the other hand, the legal implications can lead to unnecessary caution and defensive medicine. While securing patients compensation in cases of negligence, the very same legislation creates incentives for defensive medicine.

The question is whether liability fears are warranted concerns for Swiss physicians in the event that they do not recommend a PSA test and the patients are later diagnosed with prostate cancer. Whereas the legal system in the USA is case based and in principle the accused has to demonstrate his innocence, legal practice is generally based on written laws and the plaintiff has to provide evidence that the accused is guilty. In Switzerland and Germany, according to criminal law, a physician can be convicted for not ordering a test only if there is an utmost probability that omission of the test leads to death. Under civil law, the plaintiff also has to prove that not ordering the PSA test is causal to the damages incurred. Therefore, apart from if they have made major treatment errors, physicians rarely have to fear being convicted for not ordering a test with unclear clinical relevance, such as PSA, and the risk of their having to pay damages is slight. Nevertheless, physicians tend to act proactively to avoid being blamed by patients for having failed to do the test or out of fear that patients' solicitors will take legal measures. Their overdiagnosis is consistent with the overtreatment observed among Swiss gynaecologists, who perform hysterectomies on $16 \%$ of the general public, compared with only $10 \%$ on wives of physicians [14]. 
A limitation of our study is that participants were not a randomly assembled group of physicians, but a selection of physicians attending a continuing medical education congress. The response rate of $45 \%$ might have introduced selection bias and could have led to over- or underestimation of the average general physician's knowledge about the effectiveness of prostate cancer screening and the recommendation rate. A further limitation is that the data on recommendations are based on self-reports and may under- or overestimate actual practice. Despite these limitations, we were able to demonstrate that legal concerns are a factor in some Swiss physicians' decisions to order tests.

Our study shows that defensive medicine is not a phenomenon particular to the USA, but is also observable in Switzerland, where the number of malpractice litigations is lower. This result is surprising, given that in Switzerland and other European countries, physicians who do not recommend a test or medical intervention whose effectiveness is controversial need not fear litigation.

\section{References}

1. Hurwitz, B. (2004) How does evidence based guidance influence determinations of medical negligence? British Medical Journal, 329 (7473), 1024-1028.

2. Atkins, D., Siegel, J. \& Slutsky, J. (2005) Making policy when the evidence is in dispute. Health Affairs, 24 (1), 102-113.

3. King, J. S. \& Moulton, B. W. (2006) Rethinking informed consent: the case for shared medical decision-making. American Journal of Law \& Medicine, 32 (4), 429-501.

4. Hyman, D. A. \& Silver, C. (2006) Medical malpractice litigation and tort reform: it's the incentives, stupid. Vanderbilt Law Review, 59 (4), 1085-1136.
5. Gorman, C. (2007) Are doctors just playing hunches? Time magazine, 15 February 2007. Available from: http://www.time.com/time/ magazine/article/0,9171,1590448,00.html (last accessed 25 February 2009).

6. Merenstein, D. (2004) A piece of my mind. Winners and losers. JAMA, 291 (1), 15-16.

7. Lapp, T. (2005) Clinical guidelines in court: it's a tug of war. American Academy of Family Physicians Report, 2005. Available at: http:// www.aafp.org/x33422.xml (last accessed 12 February 2008).

8. Studdert, D. M., Mello, M. M., Sage, W. M., DesRoches, C. M., Peugh, J., Zapert, K. \& Brennan, T. A. (2005) Defensive medicine among high-risk specialist physicians in a volatile malpractice environment. JAMA, 293 (21), 2609-2617.

9. Anderson, R. E. (1999) Billions for defense: the pervasive nature of defensive medicine. Archives of International Medicine, 159 (20), 2399-2402.

10. Naumann, G. O. H. (1998) Ophthalmology in Germany. Archives of Ophthalmology, 116 (10), 1366-1368.

11. Weymayr, C. (2004) Arzt im Unrecht. Brandeins, 9, 112-113.

12. Kessler, D. P., Summerton, N. \& Graham, J. R. (2006) Effects of the medical liability system in Australia, the UK, and the USA. Lancet, 368 (9531), 240-246.

13. Girgis, S., Ward, J. E. \& Thomson, C. J. (1999) General practitioners' perceptions of medicolegal risk. Using case scenarios to assess the potential impact of prostate cancer screening guidelines. The Medical Journal of Australia, 171 (7), 362-366.

14. Domenighetti, G., Casabianca, A., Gutzwiller, F. \& Martinoli, S. (1993) Revisiting the most informed consumer of surgical services: the physician-patient. International Journal of Technology Assessment in Health Care, 9 (4), 505-513. 